\title{
Relationships of Viktimization with Extraversion, Neurotism and Psychological Gender
}

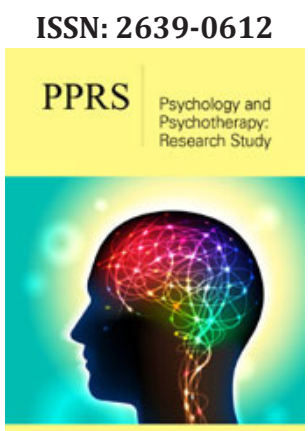

*Corresponding author: Victor P Sheinov, Professor of psychology and pedagogical mastery, Belarus

Submission: 睓 November 04, 2019

Published: 僵 November 13, 2019

Volume 3 - Issue 1

How to cite this article: Victor P Sheinov. Relationships of Viktimization with Extraversion, Neurotism and Psychological Gender. Psychol Psychother Res Stud. 3(1).PPRS.000553.2019.

DOI: 10.31031/PPRS.2019.03.000553

Copyright@ Victor P Sheinov, This article is distributed under the terms of the Creative Commons Attribution 4.0 International License, which permits unrestricted use and redistribution provided that the original author and source are credited.

\author{
Victor P Sheinov* \\ Professor of psychology and pedagogical mastery, Belarus
}

\section{Introduction}

Victimization is the process and result of turning an individual into a victim of unlawful assault. The need to study victimization is explained by its wide distribution and negative consequences for its victims. The purpose of this study is to determine the nature of the relationship of victimization with extraversion, neuroticism and psychological gender.

\section{Method Used}

The Methodology for assessing the degree of victimization of an adult individual, developed by the author, Polorolei Sandra Bam questionnaire, Eysenck's personality questionnaire.

\section{Result}

General victimization, aggressive and dependent behavior of women and men are positively associated with neuroticism. The vulnerability of women (men) from manipulation is positively (negatively) associated with neuroticism. Extraversion negatively correlates with general victimization, aggressive and dependent behavior of men and positively with aggressive and uncritical behavior of women. The insecurity of men and women from manipulation is negatively associated with extraversion. General victimization, aggressive, self-destructive and uncritical behavior of men and youths are positively (and dependent behavior negatively) associated with masculinity. Victimization as a result of the self-destructive behavior of women and girls correlates positively with masculinity, and victimization as a result of addictive behavior negatively. Victimization as a result of aggressive behavior of women, men and boys is negatively associated with femininity. Women's vulnerability to manipulation is positively associated with femininity. With age, women experience a decrease in overall victimization by reducing its "aggressive behavior" components.

\section{The Discussion of the Result}

The established relationships clarify the conclusions of foreign studies, highlighting the components of victimization that implement these connections. The inconsistency of foreign results on the links between victimization and extraversion is explained by the significant influence of gender differences established in this work. The representativeness of the samples in the study was ensured by the inclusion of a large number (766) of subjects- 394 women and 372 men aged 17 to 74 years, representing different spheres of life and regions.

\section{Findings}

a. In men and women, general victimization, aggressive and dependent behavior are positively correlated with neuroticism. The vulnerability of women (men) from manipulation is positively (negatively) associated with neuroticism.

b. In men, extraversion is negatively associated with general victimization, aggressive and addictive behavior, in women-positively with aggressive and uncritical behavior. In men and women, extraversion negatively correlates with insecurity from manipulation.

c. General victimization, aggressive, self-destructive and uncritical behavior are positively associated with masculinity of men and youths, and dependent behavior is negative. 
Victimization as a result of self-destructive behavior correlates positively with masculinity of women and girls, and victimization as a result of addictive behavior is negatively correlated.

d. Victimization as a result of aggressive behavior of women, men, and youths is negatively associated with femininity. With the victimization of girls, indicators of their femininity do not correlate.
Women's vulnerability to manipulation is positively associated with femininity; in men's vulnerability to manipulation, there is no connection with femininity.

e. The overall victimization of women decreases with age due to a decrease in its victimization as a result of aggressive behavior.

For possible submissions Click below: 